\title{
Key Design Characteristics for Developing Usable E-Commerce Websites in the Arab World
}

\author{
Layla Hasan \\ Software Engineering Department, Zarqa University, \\ Zarqa, Jordan
}

\section{L.hasan2@yahoo.co.uk}

\begin{abstract}
This research aims to suggest key design characteristics that are necessary for developing usable e-commerce websites in the Arab world. A comprehensive usability evaluation of four leading Arab e-commerce websites was conducted using the heuristic evaluation method. The results identified major and minor usability problems and major and minor good design characteristics on the selected websites. Based on the results, 51 key design characteristics were suggested. The recommended key design characteristics comprised two levels according to their priority: level one which includes mandatory key design characteristics and level two which includes supplementary design characteristics. The key design characteristics in each level were categorized under specific pages and areas that can be found on any e-commerce website. Such categorizations could direct website evaluators and designers to important pages and areas that should be considered to improve the overall usability of e-commerce websites. The results of this research are particularly important to developing countries which are still facing challenges that may affect the design and accessibility of usable and useful websites. These relate to low speed of accessing the Internet and a lack of website designers who have experience in customers' needs and websites' usable design characteristics.
\end{abstract}

Keywords: key design characteristics, usability, e-commerce websites, Arab world, heuristic evaluation, informing

\section{Introduction}

E-commerce is the process of buying, selling, or exchanging products and/or services and/or information via the Internet (Turban, King, Lee, Warkentin, \& Chung, 2002). E-commerce provides many advantages to business organisations, which include extending the marketplace of a business into national and international markets, allowing the customization of products and services according to customers' requirements, enabling companies to interact more closely with their cus-

(CC BY-NC 4.0) This article is licensed to you under a Creative Commons AttributionNonCommercial 4.0 International License. When you copy and redistribute this paper in full or in part, you need to provide proper attribution to it to ensure that others can later locate this work (and to ensure that others do not accuse you of plagiarism). You may (and we encourage you to) adapt, remix, transform, and build upon the material for any non-commercial purposes. This license does not permit you to use this material for commercial purposes. tomers, and reducing the cost (Hasan, 2009; Muhtaseb, Lakiotaki, \& Matsatsinis, 2012; Tassabehji, 2003; Turban et al., 2002). The e-commerce context can also be viewed from an informing science perspective as explained in Cohen (1999), Cohen (2009), and Gill (2008). Their work elaborates that an informing science framework consists of the informer, the delivery system, and the client (who may be also viewed as the end-user or stakeholder). Looking at the relationship among these three dis- 
tinct informing science components, we can identify the following: (1) The e-commerce vendors (referred to as informer) communicate with the customers (also may be referred to as the clients) who consume the vendor's product or service; and (2) The informer's functions are achieved via a delivery mechanism of system made of the website infrastructure, its user interface, and the communication mechanism (which in the e-commerce case is the internet).

Arab countries are still facing barriers (explained by the informing science framework, Smith \& Spiers, 2009) which affect the development and diffusion of e-commerce in these countries, such as regional instability, lack of clear regulations, payment barriers (i.e., reliance on cash instead of debit or credit cards), cultural barriers, and delivery, economic, and security barriers (Hasan, 2009; Shuqum, 2015). Fortunately, and despite the barriers that the Arab countries face regarding e-commerce, they have realized the advantages of e-commerce. Companies in the Arab world have already developed e-commerce sites, and they are already involved in e-commerce as sellers or buyers. Furthermore, recent studies showed that e-commerce in the Arab countries is growing fast (Shuqum, 2015). According to a recent study described in Shuqum (2015), e-commerce in the Arab countries was worth $\$ 14$ billion in 2014 , and it is expected to total more than $\$ 20$ billion by 2020 .

As the e-commerce market is growing rapidly in the Arab countries, it is now the responsibility of e-commerce companies to consider factors which make their e-commerce websites successful and profitable. One of the key factors that helps in part to make e-commerce websites successful is usability (Green \& Pearson, 2011). Usability was identified as: "The extent to which a product can be used by specified users to achieve specified goals with effectiveness, efficiency and satisfaction in a specified context of use" (ISO 9241-11, 1998). Nielsen and Norman (2000) stressed the importance of making e-commerce sites usable; they do not regard good usability as a luxury but as a key characteristic if a site is to survive. Nielsen (2003) also stated that the first law of ecommerce is that, if users are unable to find a product, they cannot buy it. Research has suggested advantages that can be gained if the usability of e-commerce websites is considered or improved. These include increasing the percentage of visitors who purchased from a site and who could then turn into frequent and loyal customers; increasing traffic; increasing sales; and increasing customers' trust, users' satisfaction and purchase intention (Goh et al., 2013; Lohse \& Spiller, 1998; Muhtaseb et al., 2012; Nielsen \& Norman, 2000; Rianto, Nugroho, \& Santosa, 2015; Tedeschi, 1999).

However, despite the importance of considering usability in e-commerce websites, many such sites still do not meet usability requirements (Goh et al., 2013). This is the case also for ecommerce websites in the Arab countries. Because of this, and because of the exponential growth of the e-commerce market in this area, it was thought worthwhile to conduct research concerning the usability of e-commerce websites in the Arab countries. In fact, there is currently a lack of research with regard to the usability of e-commerce websites in the Arab world. Most of the studies that were found concerned evaluations of the usability of some websites in different countries but there is a lack of research which identifies the key design characteristics that need to be considered when developing usable e-commerce in this region.

The aim of this research, therefore, is to present the key design characteristics that are necessary for developing usable e-commerce websites in the Arab world. From an informing science perspective, the focus of this article is on the delivery system (mechanism) including issues of design and human computer interface. The specific objectives for the research are:

1. To evaluate the usability of a selection of Arab e-commerce websites;

2. Based on objective 1, to determine the common strengths and weaknesses of the selected Arab websites;

3. Based on objective 2, to suggest the key characteristics that should be taken into consideration in developing usable e-commerce websites in the Arab world. 
This paper is organized as follows: the next section summarizes earlier research which evaluated the usability of e-commerce websites and shed light on both usability problems and good design characteristics on e-commerce websites. The third section summarizes the methodology used in this research while the fourth section presents the suggested key characteristics and the results of the research. The fifth section presents a discussion of the results in the light of the literature. Finally, the sixth section concludes the research.

\section{Usability Problems and Strengths on E-Commerce Websites}

Various usability evaluation methods were employed by earlier research to evaluate the usability of e-commerce websites and shed light on common usability problems and common strengths (good design features) on such sites. These methods included user testing methods where the users identified usability problems or strengths on e-commerce websites; user inspection methods, specifically heuristic evaluation, where evaluators identified user problems or strengths on ecommerce websites; or Google Analytics where software is used to predict potential usability problems or strengths on e-commerce websites. User testing methods usually involve users being observed while performing pre-defined tasks with the purpose of identifying usability problems (Brinck, Gergle, \& Wood, 2001). However, the heuristic evaluation method is the most common usability inspection method for evaluating e-commerce websites (Goh et al., 2013).This method involves a number of evaluators who assess the user interface and judge whether it conforms to a set of usability principles (namely 'heuristics') (Nielsen \& Molich, 1990). Finally, Google Analytics involves adding lines of script (e.g., JavaScript) to the pages of a website to gather statistics from them to understand visitors' experiences and therefore predict potential usability problems on an e-commerce website. This section presents earlier research which employed the various usability evaluation methods to evaluate the usability of e-commerce websites.

The study conducted by Freeman, Hyland, and Soar (2003), for example, involved user testing methods in evaluating and comparing the usability of three supermarket sites that sold multiple products. The results identified various usability problems on the three sites, which included not being easy to find products, illogical and inconvenient placement of buy link/button, not being easy to add an item to the shopping cart, not being easy to change the quantity in the shopping cart, and an ordering process that was not easy to complete.

Also, Goh et al. (2013) evaluated the usability of an online gift shop in Malaysia using user testing methods. The results revealed the major usability problems that were found on the site. These related to difficulty to sign up to the site, unavailability of a comparison tool to compare the prices of the products, and the use of a small font on the site's pages.

As an alternative, Hasan, Morris, and Probets (2013) suggested a methodological usability evaluation approach for e-commerce websites in developing countries. To develop the framework, Hasan et al. (2013) evaluated the usability of three Jordanian e-commerce websites using three usability methods (user testing methods, heuristic evaluation method, and Google Analytics), and provided a detailed explanation of the usability problems that were found on the tested websites. Examples of the problems were misleading links, links that were not obvious, weak navigation support, inaccurate results from the internal search, poor structure, illogical categorization of menu items, irrelevant content, missing information about the products, misleading images, inappropriate page design, inappropriate choice of fonts and colors, long ordering process, and compulsory registration.

The above studies proved the usefulness of employing user testing methods, heuristic evaluation, and Google Analytics in evaluating the usability of e-commerce websites. However, these studies focused only on identifying usability problems on e-commerce websites; they did not aim to pre- 
sent common strengths on the tested sites. Alternatively, some studies were found in the literature which shed light on both usability problems and good design features on e-commerce websites. For example, in Tilson, Dong, Martin, and Kieke's study (1998), the researchers employed the user testing method and asked sixteen users to complete tasks on four e-commerce websites and report what they disliked and liked. Major design problems encountered by users while interacting with the sites were identified. These included lack of pictures of the products, missing information about products, cluttered information, not obvious order buttons/links, not displaying a running total on the shopping cart, and not being able to edit the quantity in the shopping cart easily. Alternatively, major good design features that users liked on the e-commerce websites were identified. These included simple and clear product menus, few clicks to purchase products, helpful categorization of products, and providing comparison features.

Also, Barnard and Wesson $(2003 ; 2004)$ employed both user testing and heuristic evaluation methods together to investigate and identify usability problems, as well as to determine design issues that were significant for e-commerce sites in South Africa. Several usability problems were identified on the selected South African e-commerce sites. Furthermore, common strengths were identified. The problems included inappropriate design of the product listing pages, unavailability of product comparisons, inadequate product descriptions, lack of information on product availability, inadequate information about the company, and unpleasing design of the sites. However, the common good features included home page that gave a clear indication of what the site sold, text on the screen that was easy to read, language that was easy to understand, and providing payment details was simple.

Furthermore, Chen and Macredie (2005) employed the heuristic method to investigate the usability of four electronic supermarkets. The results revealed common usability problems and common strengths on the websites. Examples of the common usability problems that were identified were not being easy for users to switch between help and work and a lack of clear help and support for users. Examples of the common strengths that were identified included aesthetic and minimalist design where clear information was displayed on each page and the effective use of colors on the site's pages.

The literature proved the usefulness of employing various usability evaluation methods in identifying usability problems or strengths on e-commerce websites. However, it shows that there is a lack of recent research which concerns identifying key usability problems and key good design features on Arab e-commerce websites. The literature shows also that little research has been undertaken that concerns the usability of e-commerce in the Arab world. Furthermore, no research has been conducted to evaluate the usability of e-commerce websites in this region in order to suggest key design characteristics that should be considered to develop successful Arab ecommerce websites.

\section{Methodology}

The most common usability inspection method for evaluating e-commerce websites, which is the heuristic evaluation method, was employed in this research. This method was used because of its speed and affordability in identifying large numbers of usability problems and because of its relatively low cost (Pearrow, 2000; Simeral \& Branghan, 1997). However, the evaluators in the heuristic evaluation method do not represent real or representative users and for this they might not be able to identify real usability problems which users face when interacting with an interface (Stone, Jarrett, Woodroffe, \& Minocha, 2005). This is considered one of the key limitations of employing the heuristic evaluation method. Comprehensive heuristics, specific to e-commerce websites, were used in this research. They were developed based on an earlier study which developed specific heuristics for e-commerce websites (Hasan, 2009) and from other research which suggested important design features when designing e-commerce websites (Goh et al., 2013; 
Nielsen, 1999; Nielsen \& Loranger, 2006; Nielsen \& Tahir, 2001). The adapted heuristics included six major categories. Table 1 displays the categories and subcategories of the adapted heuristic.

Table 1. The categories and subcategories of the adapted heuristics

\begin{tabular}{|l|l|}
\hline \multicolumn{1}{|c|}{ Category } & \multicolumn{1}{c|}{ Subcategories } \\
\hline Navigation and Links & $\begin{array}{l}\text { Navigation support; working links; no broken links; no orphan pages; effective } \\
\text { internal search function }\end{array}$ \\
\hline Architecture & Logical architecture of site; simple architecture; simple navigation menu \\
\hline Content & $\begin{array}{l}\text { Current information; appropriate information; no under-construction pages; } \\
\text { grammatical accuracy; information about the company; information about the } \\
\text { products }\end{array}$ \\
\hline $\begin{array}{l}\text { Accessibility and } \\
\text { Communication }\end{array}$ & $\begin{array}{l}\text { Easy to find a website; contact us information; quick downloading of web pages; } \\
\text { foreign language support; currency support }\end{array}$ \\
\hline Design & $\begin{array}{l}\text { Consistency; appropriate use of images; appropriate choice of fonts and colors; } \\
\text { appropriate page design }\end{array}$ \\
\hline Purchasing Process & $\begin{array}{l}\text { Easy order process; ordering information; delivery information; availability of } \\
\text { alternative methods of ordering/ payment/delivery; security; privacy }\end{array}$ \\
\hline
\end{tabular}

Four key Arab e-commerce websites were selected for the purpose of this research based on success criteria. These websites were the leading e-commerce websites in the Arab world which had the greatest number of visitors and customers (Paypal, 2013). These websites offered the customers products sometimes at better prices, with delivery faster than in shops, and were able to make thousands more products available, both internationally and locally (Paypal, 2013). These factors were considered as success factors for e-commerce websites in the Arab world and therefore the four websites were selected as the sample to conduct this research based on success criteria. The key leading Arab e-commerce websites were Souq.com, Sukar.com, Namshi.com, and MarkaVIP.com. Souq.com, Sukar.com, and Namshi.com are e-commerce websites which were launched in the UAE in 2005, 2010, and 2011, respectively. However, MarkaVIP.com is a Jordanian ecommerce website which was established in 2010. These e-commerce websites offer a large number of products across various categories including fashion, watches, beauty products and footwear.

Four evaluators participated in this research: two usability specialists and two web experts. Each of the four evaluators evaluated the four e-commerce websites in four different sessions. The heuristic sessions followed a similar procedure. In each session the evaluators were asked to visit the website twice. At the beginning of each session, the evaluator was asked to explore the tested website for 15 minutes and then try to buy anything from this site. After the exploration, the heuristic guidelines, presented in Table 1, were given to him/her to be used as guidelines while evaluating each website. The evaluator was asked to read each category and subcategory of the heuristic and its explanation and to write down his/her comments concerning whether or not the website complied with each heuristic principle, as well as to offer any additional comments. The evaluators were also asked to determine whether the identified problem or strength design factor on each website was major or minor. Major problems were identified as mistakes which would prevent the user from interacting with the website and buying from it successfully, while minor problems were identified as mistakes which the user might face while interacting with a site, but which would not prevent him/her from completing the tasks on the website successfully. Alternatively, major design factors were identified as the design features that should be included in the website to enable the user to interact with the site successfully, while minor design factors were identified as supplementary design features which could improve the design of the website. The evaluation included examining the Arabic and English interfaces of the four selected e-commerce 
websites. The evaluations were carried out independently by each evaluator and completed over three months (June 2014 to August 2014).

The evaluators' comments on the compliance of each site to each heuristic principle were grouped together for each site and then organized under the categories and sub-categories of the heuristic guidelines. Each heuristic sub-category of each website was examined to identify problems and strengths and their severity (major, minor). The problems and strengths were then classified. Similar problems and similar strengths were grouped together and examined to identify common areas of usability problems and common areas of good design across the four websites, together with their seriousness (major, minor). Then, these results were used to develop recommendations (key characteristics) that should be taken into consideration in order to develop usable Arab e-commerce websites. The recommendations were divided into mandatory and supplementary ones based on the major and minor usability problems and good design features that were found by the evaluators on the tested Arab e-commerce websites. The section on the key characteristics for usable e-commerce websites presents the recommendations, the major and minor usability problems, and the good design features that were behind the recommendations.

\section{Key Characteristics for Usable E-Commerce Websites}

The results of this research suggest certain key characteristics that should be included in order to develop usable e-commerce websites, specifically in the Arab world. The key characteristics are divided into two levels, mandatory and supplementary, based on the seriousness of the usability problems and good design characteristics that were found by the evaluators on the tested Arab ecommerce websites. Level one, which was based on the major problems and major strong design characteristics that were identified on the tested e-commerce websites, included 29 major design characteristics that ought to be considered when developing usable e-commerce websites. However, level two, which was based on the minor problems and minor design characteristics that were found on the e-commerce websites, included 22 minor design characteristics that would complement the major characteristics but had lesser priority when compared to the major design characteristics. This section presents the mandatory and supplementary design characteristics that could be taken into considerations to improve the overall usability of Arab e-commerce websites. It also explains the results of this research which support these recommendations.

\section{Level One: Mandatory Design Characteristics (Informing Science Delivery Mechanism)}

This sub-section presents the mandatory design characteristics that were developed based on the major usability problems and major strong design characteristics that were found on the tested Arab e-commerce websites. These mandatory design characteristics, which represent mandatory recommendations, are divided into two parts based on their potential location on an e-commerce website: i.e., specific pages on an e-commerce website and on the website as a whole. The recommendations under the heading of "whole website" represent recommendations which affected more than one page on an e-commerce website. Table 2 presents 29 mandatory recommendations based on their potential location on an e-commerce website, 17 recommendations on specific pages, and 12 recommendations relating to the whole website. The specific pages relate to eight pages that are part of any e-commerce website, while the recommendations relating to the whole website are categorized into nine areas depending on their content (Table 2). Table 2 also presents the number of major usability problems or major good design characteristics found on each of the four tested e-commerce websites, which support each recommendation. It should be noted that the highlighted rows in Table 2 represent recommendations which are based on major strong design factors, while un-highlighted rows represent recommendations which are based on major usability problems. 
Table 2. Mandatory design characteristics based on their potential location on an ecommerce website, together with the number of major usability problems or major good design characteristics that were found on each of the four e-commerce websites.

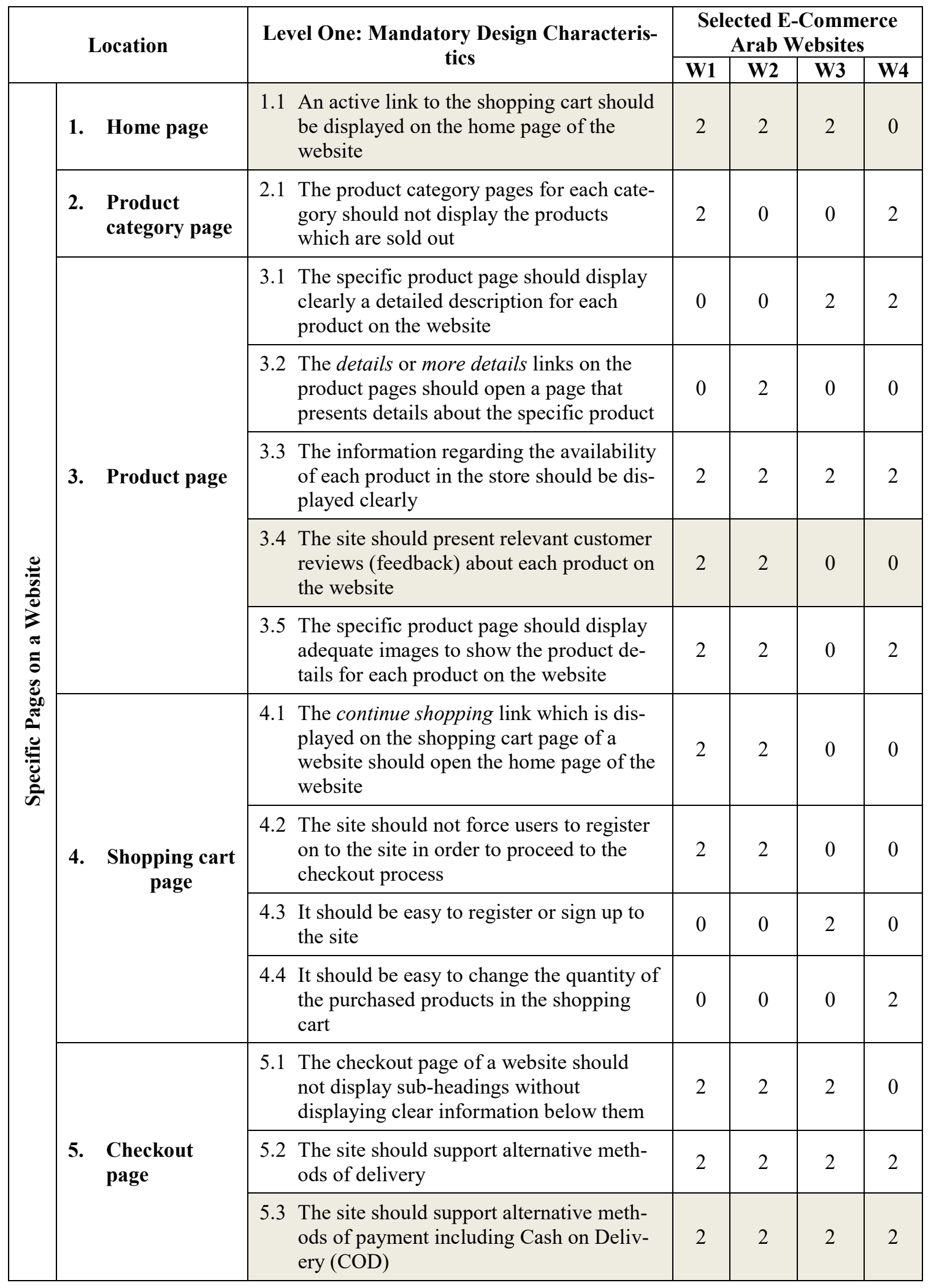




\begin{tabular}{|c|c|c|c|c|c|c|}
\hline & 6. About us page & $\begin{array}{l}\text { 6.1 The website should include a dedicated } \\
\text { "About us" page }\end{array}$ & 2 & 2 & 2 & 2 \\
\hline & 7. Help page & $\begin{array}{l}\text { 7.1 The user must be able to open the help } \\
\text { page in the website without forcing } \\
\text { him/her to register with the website }\end{array}$ & 0 & 2 & 2 & 0 \\
\hline & $\begin{array}{l}\text { 8. Contact us } \\
\text { page }\end{array}$ & $\begin{array}{l}\text { 8.1 The Contact us page should display useful } \\
\text { information to enable easy communica- } \\
\text { tion with the company e.g., physical ad- } \\
\text { dress, telephone or fax numbers }\end{array}$ & 2 & 2 & 0 & 0 \\
\hline \multirow{12}{*}{$\begin{array}{l}\frac{\pi}{0} \\
\frac{0}{0} \\
\frac{0}{0} \\
\frac{0}{0} \\
\frac{2}{2} \\
2\end{array}$} & $\begin{array}{l}\text { 9. Internal } \\
\text { search func- } \\
\text { tion }\end{array}$ & $\begin{array}{l}\text { 9.1 There must be an effective and accurate } \\
\text { internal search function on the website }\end{array}$ & 2 & 2 & 2 & 2 \\
\hline & $\begin{array}{l}\text { 10. Top menu of } \\
\text { the website }\end{array}$ & $\begin{array}{l}\text { 10.1 The total price of the items in the shop- } \\
\text { ping cart should be displayed accurately } \\
\text { on the shopping cart item that is usually } \\
\text { displayed on the top menu of the website }\end{array}$ & 2 & 2 & 2 & 0 \\
\hline & $\begin{array}{l}\text { 11. Shipping in- } \\
\text { formation }\end{array}$ & $\begin{array}{l}\text { 11.1 Accurate information concerning the } \\
\text { countries to which the site supports ship- } \\
\text { ping should be displayed on the website's } \\
\text { pages }\end{array}$ & 0 & 2 & 0 & 0 \\
\hline & $\begin{array}{l}\text { 12. Ordering } \\
\text { process }\end{array}$ & $\begin{array}{l}\text { 12.1 The ordering process should not be long } \\
\text { and not have repetitive steps }\end{array}$ & 2 & 2 & 0 & 2 \\
\hline & \multirow{3}{*}{$\begin{array}{l}\text { 13. Website's } \\
\text { content }\end{array}$} & $\begin{array}{l}\text { 13.1 The information on the website's pages } \\
\text { should be up-to-date and frequently up- } \\
\text { dated }\end{array}$ & 2 & 2 & 2 & 2 \\
\hline & & $\begin{array}{l}\text { 13.2 The content of the website's pages should } \\
\text { be grammatically accurate and should not } \\
\text { contain grammatical errors or misspell- } \\
\text { ings }\end{array}$ & 2 & 2 & 2 & 2 \\
\hline & & $\begin{array}{l}\text { 13.3 The website's content should be written } \\
\text { using the Arabic language and be able al- } \\
\text { so to support other languages }\end{array}$ & 2 & 2 & 2 & 2 \\
\hline & \multirow{2}{*}{ 14. Accessibility } & $\begin{array}{l}\text { 14.1 The download time of the website's pag- } \\
\text { es should not be too long }\end{array}$ & 0 & 0 & 2 & 2 \\
\hline & & $\begin{array}{l}\text { 14.2 The website should be easily identifiable } \\
\text { and accessible from search engines }\end{array}$ & 2 & 2 & 2 & 2 \\
\hline & 15. Images & $\begin{array}{l}\text { 15.1 The website should not include broken } \\
\text { images }\end{array}$ & 2 & 2 & 2 & 2 \\
\hline & $\begin{array}{l}\text { 16. Ordering, } \\
\text { delivery and } \\
\text { payment in- } \\
\text { formation }\end{array}$ & $\begin{array}{l}\text { 16.1 Complete information about ordering, } \\
\text { delivery and payment should be clearly } \\
\text { displayed on the website and should be } \\
\text { accessible from all pages of the website }\end{array}$ & 2 & 2 & 2 & 2 \\
\hline & $\begin{array}{l}\text { 17. Security and } \\
\text { privacy }\end{array}$ & $\begin{array}{l}\text { 17.1 Information about security and privacy } \\
\text { policies should be clearly displayed on the } \\
\text { website; this should be accessible from all } \\
\text { pages of the website }\end{array}$ & 2 & 2 & 2 & 2 \\
\hline
\end{tabular}




\section{Mandatory design characteristics on specific pages}

\section{Home page}

1.1 An active link to the shopping cart should be displayed on the home page of the website

This recommendation was suggested based on major strong characteristics that were identified on the websites. The evaluators found that three of the Arabic websites had this strong factor: an active link to the shopping cart through the home page of the websites.

\section{Product category page}

2.1 The product category pages for each category should not display the products which are sold out

This recommendation was identified based on major problems that were found on two of the Arab websites and related to the fact that the websites of Sukar.com and MarkaV-

IP,com displayed products which had sold out. Figure 1 shows the product category page for a women's wallet product on Sukar.com. This shows that the wallets were sold out.

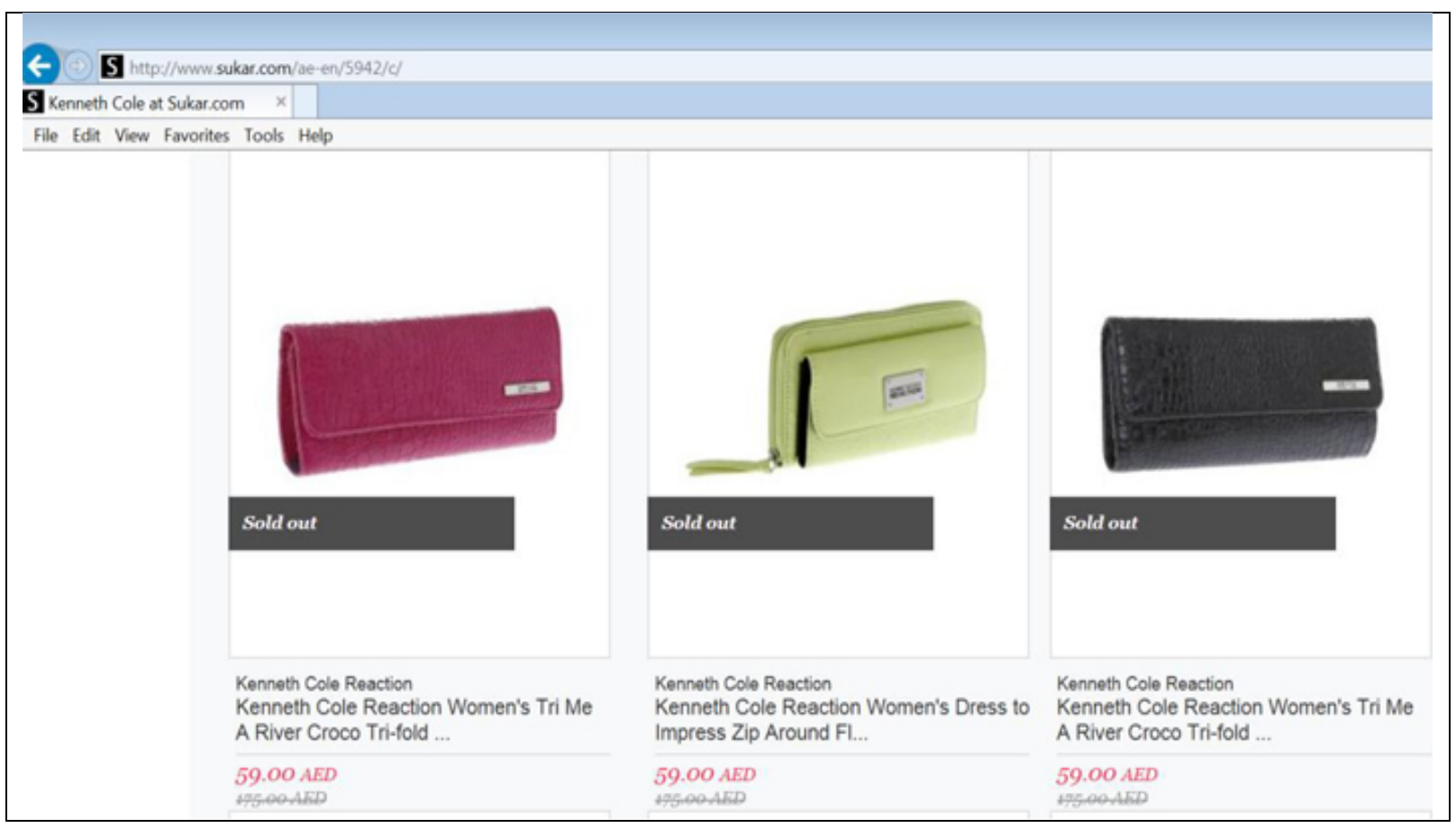

Figure 1. A product category page for a women's wallet product on Sukar.com which shows that the wallets had sold out.

\section{Product page}

3.1 The specific product page should display clearly detailed description for each product on the website

This recommendation was identified since a major problem relating to missing descriptions of products was found on two of the Arab websites. The product pages for these websites did not display descriptions in sufficient detail regarding some of their products. For example, the product pages for some products on the two websites were empty.

\subsection{The details or more details links on the product pages should open a page that pre-} sents details about the specific product

This recommendation was identified since a major problem was found on the Sukar.com website and related to the details link on the product pages. This link is supposed to open 
a page which presents additional details about a specific product before purchasing but it did not work; it stayed on the same page.

\subsection{The information regarding the availability of each product in the store should be} displayed clearly

This recommendation was suggested since a major problem was identified on all the Arab e-commerce websites and related to the fact that the websites did not display the number of products available in the store for each product.

\subsection{The site should present relevant customer reviews (feedback) about each product on} the website

This recommendation was suggested based on a major strength that was identified on two Arab websites. This major factor relates to the display of relevant customer reviews (feedback) on the specific product page regarding similar products that have been purchased from the website.

\subsection{The specific product page should display adequate images to show the product de-} tails for each product on the website This recommendation was suggested since a major problem was found on three of the Arab websites. The evaluators found that the product page on the three Arab websites did not display adequate images to show the product details.

\section{Shopping cart page}

4.1 The continue shopping link which is displayed on the shopping cart page of a website should open the home page of the website

This recommendation was suggested since the evaluators identified a major problem with the continue shopping link which was displayed on the shopping cart page of the Souq.com and Sukar.com websites. This link opened the product category page of the last product that had been added to the shopping cart instead of opening the home page of the websites as the user expected. Figure 2 shows the shopping cart page on Souq.com, where a Samsung mobile phone was added to the shopping cart. Figure 3 shows the product category page of Samsung mobile phones which was opened after clicking on the continue shopping link shown in Figure 3.

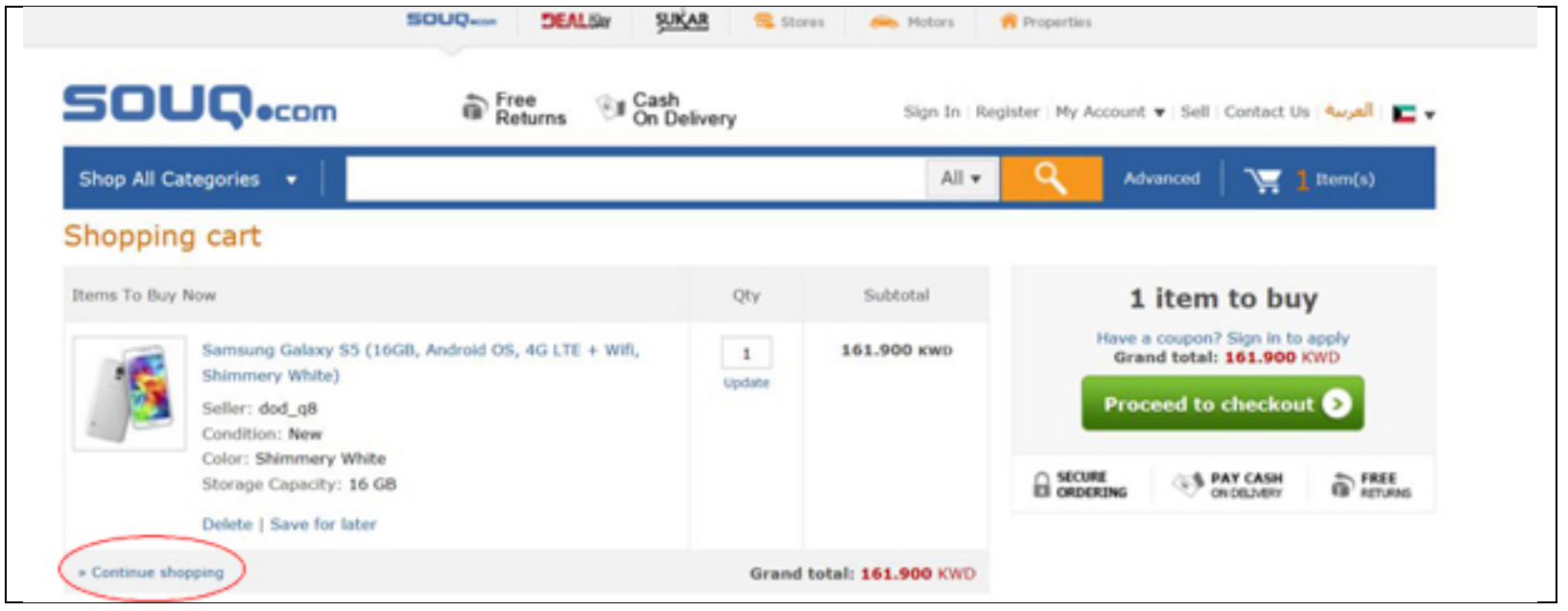

Figure 2. The shopping cart page on Souq.com where a Samsung mobile phone was added to the shopping cart. 


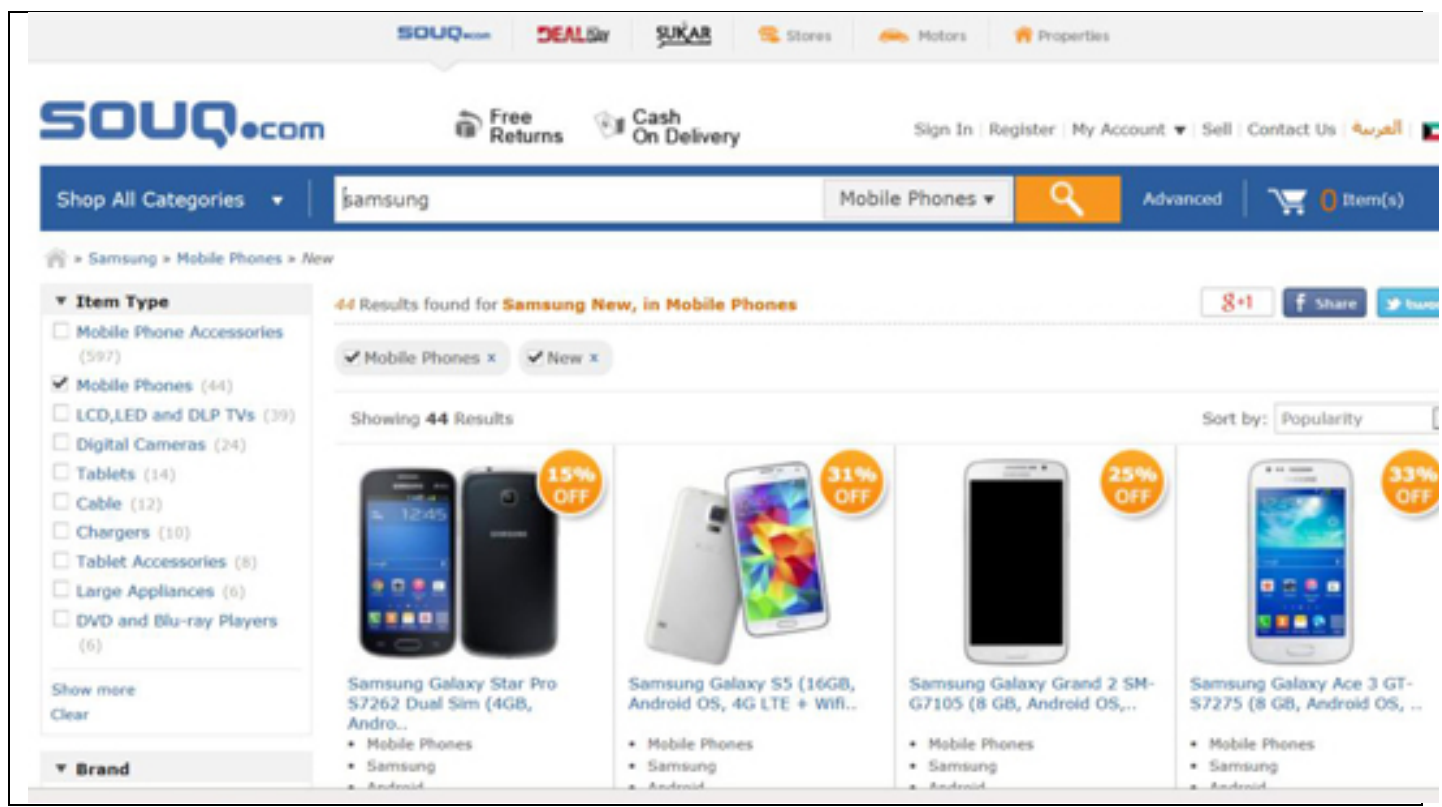

Figure 3. The product category page of Samsung mobile phones which was opened after clicking on the continue shopping link.

4.2 The site should not force users to register on to the site in order to proceed to the checkout process

This recommendation was suggested based on a major problem that was identified on two Arab e-commerce websites. These websites forced users to register with the site in order to proceed to the checkout process. The checkout link on the shopping cart page opened a page that required the user to register on to the website.

\subsection{It should be easy to register or sign up to the site}

This recommendation was suggested based on a major problem that was found on Namshi.com. The evaluators indicated that they faced difficulties while registering or signing up to the site in order to proceed to the checkout process.

\subsection{It should be easy to change the quantity of the purchased products in the shopping} cart

This recommendation was suggested since a major problem was found by the evaluators on MarkaVIP.com. This related to difficulties in interacting with the website in terms of changing the quantity of the purchased products in the shopping cart.

\section{Checkout page}

5.1 The checkout page of a website should not display sub-headings without displaying clear information below them

This recommendation was suggested since the evaluators found a major problem on the checkout page of three Arab e-commerce websites: Souq.com, Sukar.com and Namshi websites. The problem related to the fact that the checkout page on these three websites displayed two sub-headings for delivery and payment without displaying any information below them.

\subsection{The site should support alternative methods of delivery}

This recommendation was suggested based on a major problem that was found by the evaluators on all the tested Arab websites. The evaluators found that all the tested Arab websites did not support alternative methods of delivery. 
5.3 The site should support alternative methods of payment

This recommendation was suggested since the evaluators identified a strength on all the tested Arab websites. It was found that all the tested Arab websites supported alternative methods of payment.

6 About us page

6.1 The website should include a dedicated "About us" page

This recommendation was suggested since the evaluators found a major strength on all the tested Arab websites. All the websites included an About us page which displayed sufficient information about the company.

$7 \quad$ Help page

7.1 The user must be able to open the help page in the website without being forced to register with the website

This recommendation was suggested based on a major problem that was identified by the evaluators of two Arab websites. This is related to the fact that opening the help page requires the user to sign into the website instead of opening a detailed page that helps the user.

\section{Contact us page}

8.1 The contact us page should display useful information to enable easy communication with the company, e.g., physical address, telephone or fax numbers

This recommendation was suggested based on the identification of a major problem on two Arab websites. For example, the contact us page on Souq.com did not include the physical address, telephone numbers or fax numbers of Souq.com company. This page included only a form to be filled in by the user regarding his/her problem.

\section{Mandatory design characteristics on the whole website}

9. Internal search function

9.1 There must be an effective and accurate internal search function on the website This recommendation was suggested since all the evaluators identified a major problem on all the tested Arab websites regarding an internal search function for the e-commerce websites. On all the sites, this was ineffective and provided inaccurate results.

10. Top menu of the website

10.1 The total price of the items in the shopping cart should be displayed accurately on the shopping cart item that is usually displayed on the top menu of the website This recommendation was suggested based on the fact that the total price of the items in the shopping cart was not displayed on the shopping cart item that was displayed on the top menu of the websites. This problem was identified on three of the Arab websites.

\section{Shipping information}

11.1 Accurate information concerning the countries to which the site supports shipping should be displayed on the website's pages

This recommendation was identified because of a major problem which was identified on one Arab website: Sukar.com. This related to the fact that the website displayed a message on different pages stating that the site ships to seven Arab countries: Saudi Arabia, Kuwait, Qatar, UAE, Jordan, Egypt, and Bahrain. However, it ships only to UAE. Unfortunately, the site allowed the user from any country other than the UAE to add products to his/her shopping cart and proceed in the purchasing process until he/she arrived at the shipping address page where he/she could fill in his/her address. After the user clicked on "next", an error message was displayed explaining that the site ships only to UAE. 


\section{Ordering process}

12.1 The ordering process should not be long and should not have repetitive steps This recommendation was identified based on a major problem that was faced by the evaluators while trying to purchase a product from three Arab websites. The evaluators found that the ordering process of the three websites was long and repetitive.

13. Website's content

13.1 The information on the website's pages should be up-to-date and frequently updated

This recommendation was suggested because of a major strength which was found on all the tested Arab websites. This is related to the fact that all the tested Arab websites displayed up-to-date information.

13.2 The content of the website's pages should be grammatically accurate and should not contain grammatical errors or misspellings

This recommendation was suggested based on a major strength which was found on all the tested Arab websites. This is related to the fact that the content of all the tested Arab websites' pages were free from grammatical errors or misspellings.

13.3 The website's content should be written using the Arabic language but should also be able to support other languages

This recommendation was suggested because of a major strength which was identified on all the tested Arab websites. This relates to the fact that the entire content of all the Arab websites supported the Arabic language; they displayed their content in both English and Arabic.

\section{Accessibility}

14.1 The download time of the website's pages should not be too long This recommendation was suggested based on a major problem that was identified on two Arab websites. It relates to the download time of the pages which was inappropriate; it was too long.

14.2 The website should be easily identifiable and accessible from search engines This recommendation was suggested because of a major strength which was identified on all the tested Arab websites. This is related to the fact that it was easy to find and access the four tested websites using search engines.

15. Images

15.1 The website should not include broken images

This recommendation was suggested based on a strength that was found on all the tested Arab websites. The evaluators found that none of the tested Arab websites had broken images at any point.

\section{Ordering, delivery and payment information}

16.1 Complete information about ordering, delivery and payment should be clearly displayed on the website and should be accessible from all pages on the website This recommendation was suggested since all the evaluators identified a major strength on all the tested Arab websites. All the websites displayed sufficient information regarding ordering information, delivery information and payment. This information was easily accessed from any page on the websites. 


\section{Security and privacy}

17.1 Information about security and privacy policies should be clearly displayed on the website; it should be accessible from all pages on the website

This recommendation was suggested based on a major strength that was found on all the tested Arab websites. The evaluators found that all the tested Arab websites displayed clear information about the four websites' security and privacy policies. Such information was easy to access from any page of the websites.

\section{Level Two: Supplementary Design Characteristics}

This sub-section presents 22 supplementary design characteristics that were developed based on the minor usability problems and minor good design characteristics that were found on the tested Arab e-commerce websites. These supplementary recommendations represent recommendations which affected more than one page on an e-commerce website. The supplementary recommendations were categorized into eight areas depending on their content (Table 3). Table 3 presents the 22 supplementary recommendations together with the number of minor usability problems or minor good design characteristics which support each recommendation that were found on each of the four tested e-commerce websites. It should be noted that the highlighted rows in Table 3 represent recommendations which are based on minor good design factors, while un-highlighted rows represent recommendations which are based on minor usability problems.

Table 3. Supplementary design characteristics, together with the number of minor usability problems or minor good design characteristics that were found on each of the four e-commerce websites.

\begin{tabular}{|c|c|c|c|c|c|c|}
\hline \multirow{2}{*}{\multicolumn{3}{|c|}{ Level Two: Supplementary Design Characteristics }} & \multicolumn{4}{|c|}{$\begin{array}{c}\text { Selected E-Commerce } \\
\text { Arab Websites }\end{array}$} \\
\hline & & & W1 & W2 & W3 & W4 \\
\hline \multirow{6}{*}{$\begin{array}{l}\text { Navigation } \\
\text { and links }\end{array}$} & & $\begin{array}{l}\text { Each link on the website should have a name } \\
\text { which clearly defines the destination page which it } \\
\text { will open }\end{array}$ & 2 & 1 & 2 & 3 \\
\hline & 1.2 & $\begin{array}{l}\text { Each page should have a link which supports re- } \\
\text { turning easily to the home page of the site }\end{array}$ & 24 & 2 & 3 & 8 \\
\hline & 1.3 & Each link should open the desired destination page & 2 & 0 & 1 & 0 \\
\hline & 1.4 & $\begin{array}{l}\text { Links should be placed in an obvious location on } \\
\text { each page }\end{array}$ & 2 & 0 & 1 & 0 \\
\hline & 1.5 & The website's pages should not have broken links & 0 & 0 & 0 & 6 \\
\hline & 1.6 & $\begin{array}{l}\text { The website should not include orphan pages (pag- } \\
\text { es without a link) }\end{array}$ & 2 & 2 & 2 & 2 \\
\hline $\begin{array}{l}\text { 2. Architec- } \\
\text { ture of the }\end{array}$ & 2.1 & $\begin{array}{l}\text { The organization of the navigation menu items } \\
\text { should be logical }\end{array}$ & 2 & 2 & 2 & 2 \\
\hline $\begin{array}{l}\text { and its } \\
\text { menu(s) }\end{array}$ & 2.2 & 2 The architecture of the website should be simple & 2 & 2 & 0 & 0 \\
\hline \multirow{3}{*}{$\begin{array}{l}\text { 3. Website's } \\
\text { content }\end{array}$} & 3.1 & The content of the website should not be repetitive & 2 & 2 & 10 & 2 \\
\hline & 3.2 & 2 The content on the website's pages should be clear & 6 & 8 & 11 & 0 \\
\hline & 3.3 & $\begin{array}{l}\text { The website should not include "under construc- } \\
\text { tion" or empty pages }\end{array}$ & 2 & 2 & 2 & 2 \\
\hline
\end{tabular}




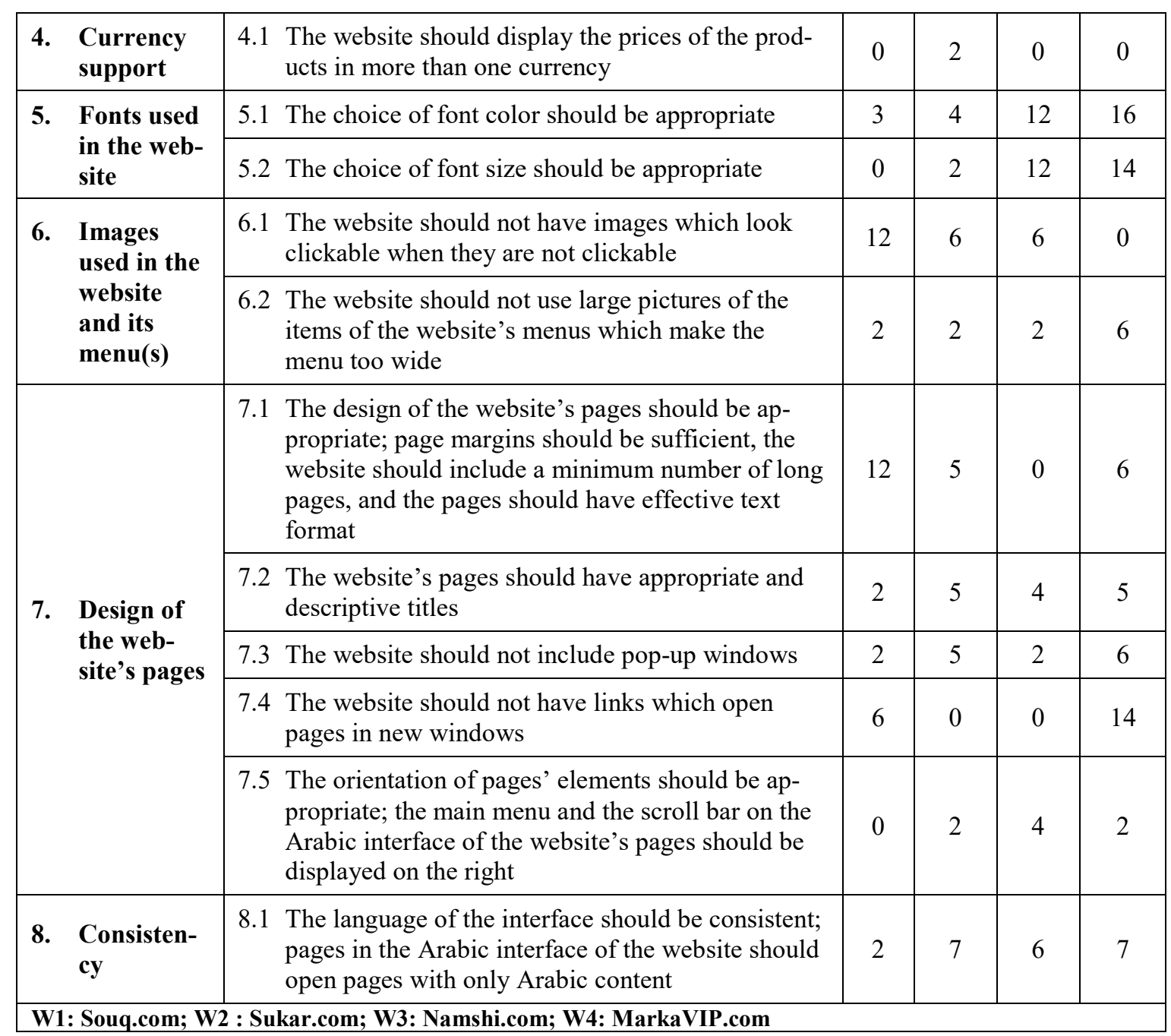

\section{Navigation and links}

\subsection{Each link on the website should have a name which clearly defines the destination page which it will open}

This recommendation was suggested based on minor problems that were identified by the evaluators on two Arab websites. The problems related to the fact that some pages in the two websites had links with link names which did not indicate clearly the destination pages which they would open.

\subsection{Each page should have a link which supports returning easily to the home page of the site}

This recommendation was suggested because of minor problems related to weak navigation support that were found on all the Arab websites. The evaluators found that it was not easy to return to the home page from some pages in the websites.

\subsection{Each link should open the desired destination page}

This recommendation was suggested based on minor problems that were identified on two Arab websites. These problems related to links that, when clicked, did not open the destination page; they stayed on the same page.

\subsection{Links should be placed in an obvious location on each page}


This recommendation was suggested based on the identification of minor problems on two Arab websites. This is related to links that were not placed in an obvious location.

\subsection{The website's pages should not have broken links}

This recommendation was suggested because of minor problems relating to broken links that were found only on one Arab website. The evaluators found that one Arab website had pages which included six broken links.

\subsection{The website should not include orphan pages (i.e., pages without a link)}

This recommendation was suggested based on the identification of a minor strength that was identified on all the Arab websites. This is related to the fact that all the tested Arab websites did not have pages without a link.

\section{Architecture of the website and its menu(s)}

\subsection{The organization of the navigation menu items should be logical}

This recommendation was suggested because of minor problems that were identified on all the tested Arab websites concerning their navigation menus. It was found that the items of the navigation menus of the websites had illogical organization/categorization.

\subsection{The architecture of the website should be simple}

This recommendation was suggested based on the identification of minor problems regarding the architecture of two Arab websites. This related to the deep architecture of the two Arab websites where the number of clicks to reach some pages in the websites was too numerous, e.g., more than 3 links.

\section{Website's content}

\subsection{The content of the website should not be repetitive}

This recommendation was suggested because of minor problems that were identified on all the Arab websites. It was found that all the tested Arab websites displayed similar links and/or data on the various pages of the sites.

\subsection{The content on the website's pages should be clear}

This recommendation was suggested based on the identification of minor problems relating to the inappropriate content of some pages on three of the tested Arab websites. For example, the about us page at Namshi.com website displays a video which, if the user wants to open it, the following error message is displayed: the video is private.

\subsection{The website should not include "under construction" or empty pages}

This recommendation was suggested based on a minor strength that was identified on all the tested Arab websites. This relates to the fact that all the tested Arab websites did not have "under construction" pages.

\section{Currency support}

4.1 The website should display the prices of the products in more than one currency This recommendation was suggested because of a minor problem that was found on one of the Arab tested websites. The evaluators indicated that, despite the fact that Sukar.com website had eight interfaces targeting eight Arab countries, these interfaces did not display the prices of their products in the currency of each of the countries. The prices of the products on all the eight interfaces were displayed using the UAE currency.

\section{Fonts used in the website}

\subsection{The choice of font color should be appropriate}

This recommendation was suggested based on minor problems that were found on all the tested Arab websites. This is related to the fact that the websites did not use appropriate font colors on some of their pages; this made the text difficult to read. 


\subsection{The choice of font size should be appropriate}

This recommendation was suggested because of minor problems that were identified by the evaluators on three Arab websites. This related to the fact that the websites used a small font size on some pages.

\section{Images used in the website and its menu(s)}

6.1 The website should not have images which looked clickable when they were not This recommendation was suggested based on minor problems regarding the use of images which were found on three Arab websites and related to the fact that three out of the four tested Arab websites displayed text images which looked clickable but were not.

6.2 The website should not use large pictures of the items of the website's menus which make the menu too wide

This recommendation was suggested because of minor problems concerning the design of the websites' menus which were found on all four tested Arab websites. This related to the fact that all the Arab websites used large pictures of the items of the menus which made the menu too wide.

\section{Design of the website's pages}

7.1 The design of the website's pages should be appropriate: page margins should be sufficient, the website should include a minimum number of long pages, and the website's pages should have an effective text format

This recommendation was suggested based on minor problems that were found on three of the tested Arab websites. It related to the fact that the three websites had problems regarding the design of their pages. These included the following: some pages were too long, the pages' margins were insufficient, the pages had long empty white spaces, the pages had ineffective text format.

7.2 The website's pages should have appropriate and descriptive titles This recommendation was suggested because of two types of minor problems that were identified on the tested websites regarding the titles of their pages. The first type of problem was found on one Arab website and related to the fact that the website included some pages without describing their titles. The second type of problem was identified on three Arab websites and related to the inclusion of some pages with titles which were inappropriate; the titles did not describe the content of the pages.

\subsection{The website should not include pop-up windows}

This recommendation was suggested based on minor problems that were found on all four Arab websites. All the tested Arab websites used pop-up windows for the subscription form, or the sign-in form, or the register form pages. For example, the login window at the MarkaVIP.com website and the subscription form to get offers at Sukar.com were pop-up windows.

\subsection{The website should not have links which open pages in new windows}

This recommendation was suggested because of minor problems that were found on two of the tested Arab websites. This related to fact that these websites had links which opened pages in new windows.

7.5 The orientation of pages' elements should be appropriate; the main menu and the scroll bar on the Arabic interface of the website's pages should be displayed on the right

This recommendation was suggested based on minor problems that were identified on three Arab websites concerning the orientation of pages' elements. It related to the fact that the scrollbar of the Arabic interface of pages on the three Arab websites was dis- 
played on the left side of the pages, while the scroll bar on the English interface of the pages of the three websites was displayed on the right.

\section{Consistency}

8.1 The language of the interface should be consistent; pages in the Arabic interface of the website should open pages with only Arabic content

This recommendation was suggested because of minor problems that were found on all the tested Arab websites. This is related to the fact that pages in the English interface of the four Arab websites opened pages with Arabic content, and vice versa.

\section{Discussion}

This research uniquely suggests key design characteristics that should be taken into consideration when developing usable e-commerce websites, specifically in the Arab countries, based on comprehensive evaluations of the usability of four leading Arab e-commerce websites. The identified key characteristics are composed of two levels, mandatory and supplementary, based on the seriousness of the usability problems and good design characteristics that were found by the evaluators on the tested Arab e-commerce websites. A total of 29 mandatory design characteristics were identified based on major usability problems and major good design characteristics found on the four Arab e-commerce websites. However, a total of 22 supplementary design characteristics were suggested based on the identification of minor usability problems and minor good design characteristics that were found on these websites.

This research provides helpful guidance to usability specialists and e-commerce website designers and developers regarding the use of the mandatory and supplementary recommendations by categorizing them. E-commerce designers and/or developers could investigate 17 areas on an ecommerce website to ensure they take into consideration major design characteristics instead of using a long list of recommendations. The 17 areas include eight specific pages that should be included on any e-commerce website and nine other areas that are part of any e-commerce website. The eight pages include the following: home page, product category page, product page, shopping cart page, checkout page, "about us" page, help page, and "contact us" page. The other nine areas include the following: internal search function, top menu of the website, shipping information, ordering process, website's content, accessibility, images, ordering, delivery and payment information, and security and privacy. Then, e-commerce designers and/or developers could investigate another eight areas on an e-commerce website to ensure the website design considers minor design characteristics which could improve its overall quality. The eight areas include navigation and links, architecture of the website and its menu(s), the website's content, currency support, the font used in the website, images used in the website, the design of the website's pages, and consistency.

The mandatory and supplementary characteristics complement each other in developing a usable e-commerce website in the Arab world. However, if a company has limitations of time and/or budget, then mandatory characteristics should be given high priority. It is recommended that these are taken into consideration first while developing and/or evaluating e-commerce websites. Supplementary characteristics can be considered as a second priority. This research also explains in detail the weaknesses (usability problems) and the strengths (good design characteristics) that were found on the four leading Arab e-commerce websites. These were the basis for developing the mandatory and supplementary key design characteristics.

This research is similar in certain respects to a few studies which not only shed light on common usability problems regarding e-commerce websites, but also on common strengths of such sites (Barnard \& Wesson, 2003, 2004; Chen \& Macredie, 2005; Tilson et al., 1998). However, this research uniquely categorizes the identified common usability problems and common strengths 
that were found on the websites in terms of their seriousness: major or minor. Furthermore, this research identifies a larger number of usability problems and good design characteristics on the four selected Arab e-commerce websites compared to earlier research.

A comparison between the results of this research and earlier studies which evaluated the usability of e-commerce websites showed that there were similarities between them regarding usability problems. The following show the usability problems that were identified by earlier research on e-commerce websites and that were also identified by this research on the four e-commerce websites as major problems: links which did not open the expected destination pages, difficulty in changing the quantity in the shopping cart, inaccurate internal search function, not being easy to sign up to the site, missing images about the products, missing descriptions about the products, insufficient information about the content of the shopping cart on the top menu, and inappropriate content (Barnard \& Wesson, 2003, 2004; Freeman et al., 2003; Goh et al., 2013; Hasan et al., 2013; Tilson et al., 1998).

Alternatively, the following present the usability problems that were identified by earlier research on e-commerce websites and that were also identified by this research on the four Arab ecommerce websites as minor problems: the use of a small font; long and cluttered pages; weak navigation support; links that were not obvious; deep structure; illogical organization of menu items; misleading images (Barnard \& Wesson, 2003, 2004; Freeman, et al., 2003; Goh et al., 2013; Hasan et al., 2013; Tilson et al., 1998).

These findings show that, despite the importance of designing usable e-commerce websites, Arab e-commerce companies are still not considering usability issues when developing their ecommerce sites. The common usability problems concerning e-commerce websites could be overcome if such companies simply considered earlier research which has already identified usability problems and then considered addressing important issues. Those common usability problems, and the additional problems which were identified uniquely by this research on the Arab ecommerce websites, should be taken into account in order to create usable e-commerce websites to facilitate and encourage consumers to purchase from them.

Fortunately, the results of this study, when making comparisons with the results of earlier research, showed that all the tested Arab e-commerce websites had overcome that usability problem which was identified by earlier research and related to inadequate information about the company (Barnard \& Wesson, 2003, 2004). The results of this research showed that one of the common strong design features found on all the tested 'Arab e-commerce websites was the display of a dedicated "About us" page.

Conversely, the results of this research, which revealed the common strengths of the selected ecommerce websites in terms of their design issues, are different from the results which were obtained by earlier research which also presented common strengths on e-commerce websites (Barnard \& Wesson, 2003, 2004; Chen \& Macredie, 2005; Tilson et al., 1998). As summarized in the second section, Chen and Macredie (2005) and Barnard and Wesson $(2003,2004)$ identified two common strengths on the selected e-commerce websites; these related to the effective use of font size and font colors. However, the selected Arab e-commerce websites in this study had usability problems regarding these two issues, as shown in the fourth section: inappropriate choice of font color, and font size. This suggests that importance should be accorded to these problems as other e-commerce websites in various countries are already overcoming such usability issues. However, the results of this research identified several common strengths which show how e-commerce companies are considering various good design features while developing their sites. Such common strengths should also be considered and taken into account while developing such sites.

The results of this research, which uniquely suggests key design characteristics that should be taken into consideration when developing usable e-commerce websites in the Arab world will 
help usability specialists and e-commerce website designers and developers to determine specific usability features that are more crucial to the overall usability of e-commerce websites and hence user satisfaction.

\section{Conclusion}

This research not only suggested 51 key design characteristics/ recommendations that should be considered when developing usable e-commerce website in the Arab countries, it also provided useful guidance to e-commerce website designers and/or developers regarding the use of the suggested recommendations. This research recommended that e-commerce developers and/or designers should follow the following two steps in order to improve the design of an e-commerce website. They could start evaluating an e-commerce website by testing the recommendations relating to eight specific pages on an e-commerce website and nine areas of it to ensure it conforms to the most important and highly recommended design characteristics. After this, they could check the recommendations relating to nine areas on the e-commerce website to ensure its compliance to design characteristics of a lesser priority. The results of this research, which support developing the key design characteristics, explain in detail the kind of major usability problems and major good design characteristics that were found on the tested Arab e-commerce websites, as well as the kind of minor usability problems and minor good design characteristics that were identified on these sites.

It is worth mentioning that, despite the fact that this research concerned Arab e-commerce websites, it is likely that the results can be generalized to other countries because many of the specific usability problems that were found on the tested sites were also found on e-commerce websites in other countries. However, the results of this research are more useful to countries where ecommerce is in its developing stages and where website designers may have less experience in customers' needs compared to countries where e-commerce has become a mainstream form of commerce. Such developing countries are still facing technological challenges regarding accessing the Internet and connection speeds which may be encountered by both designers and customers; these greatly influence the design of and accessibility to usable and useful websites. Therefore, this research identified a large number of key characteristics which were categorized in terms of specific pages and other areas on any e-commerce website. Such categorization facilitates the task of e-commerce website evaluators and/or designers by highlighting important areas on e-commerce websites to be tested and, therefore, could help guide them to usability attributes that are more crucial to the overall usability of websites in their countries. Also, the suggested key characteristics could contribute to the literature as comprehensive specific guidelines / heuristics that could be used to evaluate the usability of any e-commerce website.

The research, however, had four limitations that could influence the results obtained. The first relates to the websites that were used in this research, which were selected based on their success criteria rather than the existence of a range of usability problems. The key design characteristics/recommendations that were suggested were based on the usability problems found on the selected websites. These may not, therefore, be representative of all e-commerce websites in the Arab world. Other usability issues that were not present on any of the tested sites were not considered. The second limitation relates to the fact that only a small number of websites were selected (four of the leading e-commerce websites in the Arab world) to conduct this research. The third limitation relates to the fact that only the heuristic usability evaluation method was employed in this research; real users were not involved. Therefore, the usability problems identified in this research were based on the viewpoint of evaluators and not real users. The fourth limitation relates to the fact that, although this research was based on Arab e-commerce websites and the results suggested a large number of recommendations, most of the recommendations were general and not specific to the Arab e-commerce websites. Specific design considerations for cul- 
ture and language differences were covered a little. For example, Arab e-commerce websites should use an Arabic interface, the scroll bar and menu should be located on the right, and the use of a cash on delivery method of payment should be available. This is related to the fact that the evaluators, while evaluating the selected Arab e-commerce websites, were asked to use general heuristic guidelines based on earlier studies; these were specific to e-commerce websites but not specific to Arab e-commerce websites.

Because of the identified limitations, this study can be considered as an introductory study to further User Experience (UX) studies of e-commerce websites in the Arab world. It is recommended to conduct further UX studies with "real" users or customers rather than usability specialists to determine the importance of the suggested key design characteristics from their point of view with regard to the overall usability of e-commerce websites. A large number of e-commerce websites in the Arab world could be also considered. These could be selected based on the presence of a large number of usability problems. Further research should also be conducted which considers the cultural context in the design of Arab e-commerce websites from the viewpoint of both users and evaluators.

\section{Acknowledgment}

This research was funded by the Deanship of Research in Zarqa University /Jordan.

\section{References}

Barnard, L., \& Wesson, J. (2003). Usability issues for e-commerce in South Africa: An empirical investigation. In the Proceedings of SAICSIT 2003, 258-267.

Barnard, L., \& Wesson, J. (2004). A trust model for e-commerce in South Africa. In the Proceedings of SAICSIT 2004, 23-32.

Brinck, T., Gergle, D., \& Wood, S.D. (2001). Usability for the web: Designing websites that work. Morgan Kaufmann Publishers.

Chen, S., \& Macredie, R. D. (2005). The assessment of usability of electronic shopping: A heuristic evaluation. The International Journal of Information Management, 25, 516-532.

Cohen, E. B. (1999). Reconceptualizing information systems as a field of the transdiscipline informing science: From ugly duckling to swan. CIT. Journal of computing and information technology, 7(3), 213219.

Cohen, E. B. (2009). A philosophy of informing science. Informing Science: the International Journal of an Emerging Transdiscipline, 12, 1-15.

Freeman, M., Hyland, P. N., \& Soar, J. 2003. Australian online supermarket usability. In the Proceedings of the Annual Conference of the ACM Special Interest Group on Computer-Human Interaction, New Zealand Chapter, 119-120.

Gill, G. (2008). The single client resonance model: Beyond rigor and relevance. Informing Science: International Journal of an Emerging Transdiscipline, 11, 281-310.

Goh, K. N., Chen, Y. Y., Lai, F. W., Daud, S. C., Sivaji, A., \& Soo, S. T. (2013). A comparison of usability testing methods for an e-commerce website: A case study on a Malaysia online gift shop. In the Proceedings of the Information Technology: New Generations, 2013 Tenth International Conference, Las Vegas, NV, USA, 15-17.

Green, D., \& Pearson, J. (2011). Integrating website usability with the electronic commerce acceptance model. Behaviour and Information Technology, 30(2), 181-199.

Hasan, L. (2009). Usability evaluation framework for e-commerce websites in developing countries (PhD Thesis). Institutional Repository, Loughborough University. 
Hasan, L., Morris, A., \& Probets, S. (2013). E-Commerce websites for developing countries - A preliminary multi-faceted evaluation approach. Online Information Review Journal, 37(2), 231-251.

ISO 9241-11. (1998). International standard first edition. Ergonomic requirements for office work with visual display terminals (VDTs), Part11: Guidance on usability. Retrieved April 3, 2013, from http://www.iso.org/iso/catalogue detail.htm?csnumber=16883

Lohse, G., \& Spiller, P. (1998). Electronic shopping. Communications of the ACM, 41(7), 81-88.

Muhtaseb, R., Lakiotaki, K., \& Matsatsinis, N. (2012). Applying a multicriteria satisfaction analysis approach based on user preferences to rank usability attributes in e-tourism websites. Journal of Theoretical and Applied Electronic Commerce Research, 7(3), 28-48.

Nielsen, J. (1999). Designing web usability: The practice of simplicity. Indianapolis: New Riders Publishing.

Nielsen, J. (2003). Usability 101: Introduction to usability. Useit.com. Retrieved February 14, 2015, from http://www.useit.com/alertbox/20030825.html

Nielsen, J., \& Loranger, H. (2006). Prioritizing web usability. Indianapolis: New Riders Press.

Nielsen, J., \& Molich, R. (1990). Heuristic evaluation of user interfaces. In the Proceedings of CHI'90, ACM, 249-256.

Nielsen, J., \& Norman D. (2000). Web-Site usability: Usability on the web isn't a luxury. InformatioWeek, 14(January), 1-3.

Nielsen, J., \& Tahir, M. (2001). Homepage usability: 50 websites deconstructed. Indianapolis: New Riders Publishing.

Paypal. (2013). PayPal insight: E-commerce in the Middle East 2012-2015. Retrieved May 3, 2014, from https://www.paypal.fr/mobile-insights/pdf/PayPal-Insights-E-commerce-MiddleEast-2012-2015.pdf

Pearrow, M. (2000), Website usability handbook. Charles River Media.

Rianto, Nugroho L., \& Santosa P. (2015). A preliminary study to determine criteria for personalized ecommerce. In the Proceedings of CHIuXiD '15, Bandung, Indonesia, 8-10.

Shuqum, R. T. (2015). E-commerce a fast-growing trend in the Arab world. The Arab Weekly, 6, 18. Retrieved April 26, 2016, from http://www.thearabweekly.com/?id=481

Simeral, E., \& Branaghan, R. (1997). A comparative analysis of heuristic and usability evaluation methods. In the Proceedings of STC.

Smith, T. J., \& Spiers, R. (2009). Perceptions of e-commerce Web sites across two generations. Informing Science: the International Journal of an Emerging Transdiscipline, 12, 159-180.

Stone, D., Jarrett, C., Woodroffe, M., \& Minocha, S. 2005. User interface design and evaluation. The Open University, Morgan Kaufmann.

Tassabehji, R. (2003). Applying e-commerce in business. Sage Publications.

Tedeschi, B. (1999, August 30). E-Commerce report; On-line merchants find that a well-designed website can have a big impact on the bottom line. The New York Times. Retrieved from http://www.nytimes.com/1999/08/30/business/e-commerce-report-line-merchants-find-that-welldesigned-web-site-can-have-big.html? $\mathrm{r}=0$

Tilson, R., Dong, J., Martin, S., \& Kieke E. (1998). Factors and principles affecting the usability of four ecommerce sites. In the Proceedings of the 4th Conference on Human Factors and the Web (CHFW), AT\&TLabs, USA.

Turban, E., King, D., Lee, J., Warkentin, M., \& Chung, M. (2002). Electronic commerce; A managerial perspective. New Jersey: Pearson Education, Inc. 


\section{Biography}

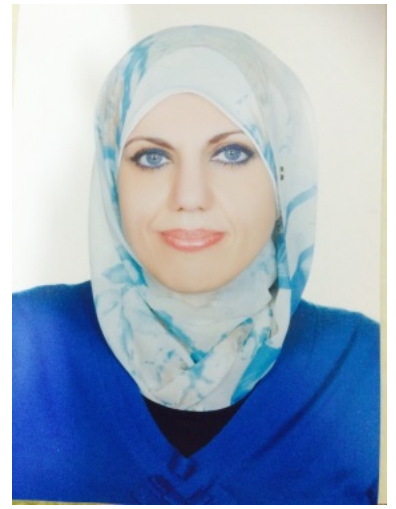

Layla Hasan is an Associate Professor in the Software Engineering Department at Zarqa University, Jordan. She holds a BSc degree in computer science from the University of Jordan, Jordan in 1996; an MBA degree in business administration from the University of Jordan, Jordan in 2004; and a PhD degree in computer science from the Loughborough University, UK in 2009. The specific area of her research is Human Computer Interaction (HCI). Her research interests include human computer interaction, usability evaluation, usability methods, and web analytics. 